\title{
DETERMINAÇÃo DA CURVA DE RETENÇÃO DE CONHECIMENTOS
}

\author{
(método de recordação) *
}

\author{
* LOURO, Leopoldo Marques \\ * * BRITO, Jorge Honório M.
}

\section{INTRODUÇÃO}

Nos planos de ensino das disciplinas de Histologia para os alunos do Curso de Odontologia, consignamos, como objetivo educacional:

"...conduzir o aluno a que, quando no estudo das disciplinas préclínicas e profissionalizantes forem evocadas células. estruturas ou tecidos orgânicos, seja ele capaz de, oral ou gràficamente, descrever-lhes seus aspectos mais significativos".

Desta forma, entre as múltiplas fracetas do problema ensino aprendizagem, a "recordação" daquilo que foi ensinado e aprendido preocupanos de modo especial.

Por este motivo, em 1967, num trabalho (1) apresentado no $10^{\circ} \mathrm{En}-$ contro Nacional de Professores de Histologia e Patologia de Faculdades de Odontologia, realizado em Florianópolis, relatamos os resultados de uma observação feita com aluros matriculados, na época, nas quatro séries do curso de Odontologia da URFGS.

Obtivemos, então, uma curva de retenção de conhecimentos muito semelhante a de EBINGHAUS. Entre- tanto, como trabalhamos com quatro turmas muito diferentes de alunos, resolvemos repetir a observação acompanhando o desempenho de um mesmo conjunto de estudantes, durante os 4 anos de seu Curso de Odontologia.

Retenção de conhecimentos é o processo de lembrar as coisas ou a capacidade para faze-lo, de maneira que as respostas ou o conhecimento uma vez adquiridos, se tornam disponíveis, em ocasiões posteriores, para uso pelo indivíduo.

MEDNICK (2) em seu livro sobı aprendizagem, focalizando os fatores que possivelmence influenciam a capacidade para reter material que é aprendido, salienta a memória como fator central. Diz o autor que não poderia haver qualquer progresso de uma prova para outra se um aprendiz não recorảasse coisa alguma da experiência anterior".

Assim sendo, é justa nossa preocupação com o destino do comportamento aprendido nas disciplinas sob nossa orientação e que procuramos verificar enquanto os estudantes estavam ao nosso alcance, isto é, durante o curso de Odontologia.

\footnotetext{
* Resumo do trabalho apresentado no 9.0 Congresso Brasileiro de Anatomia, Florianópolis, 1972 e no II Congresso Odontológico Riodandense, P. Alegre, 1972.

* Docentes Livres de Histologia e Professores Adjuntos do Departamento de Ciênclas Morfológicas do Instituto de Blo-Ciências da UFRGS.
}

(1) - EBLING, Hardy; BRITO, Jorge H. M. e LOURO, L. M. - Métodos de ensino em Histologia. P. Alegre, F/UFRGS, 1967. 21p (mimeo)

(2) - MEDNICK, Sarnoff - Aprendizagem. Rio de Janeiro, Zahar, 1967. p. 152. 
Segundo KRECH e CRUTCHFIELD (3) são três os métodos mais importantes para medir a retenção de conhecimentos:

- Método do reconhecimento, no qual o indivíduo "recorda" dentre um grande número de ítens, aqueles que aprendeu anteriormente;

- Método da reaprendizagem, usado por Ebbinghaus;

-. Método da recordação, no qual se procura verificar or quanto do aprendido é ainda lembrado, após certc espaço de tempo entre o momento de estudo e o da nova avaliação.

Com o objetivo de determinar o "quantum" daquilo que foi aprendido na disciplina de Histologia Geral o aluno consegue recordar, a medida que se afasta do momento de estudo, preferimos utilizar o último dos métocios acima indicados, empregando para tanto uma avaliação prospectiva.

\section{MATERIAL E METODOS}

Foram observados 86 alunos que, $\mathrm{cm}$ setembro de 1967 , estavam matriculados na disciplina de Histologia Geral, sendo divididos em 3 turmas, a saber :

Uma turma (T1), constituída por 19 alunos que, iniciando o curso em maio e não satisfazendo as exigências de aprovação por média, devia submeter-se à avaliação final sobre a matéria lecionada de maio a agosto.

Outra turma (T2) reunia estudantes que, tendo estudado a matéria de maio e agosto, havia sido aprovada por média, estando portando dispensada da avaliação final.

Uma terceira turma (T3), composta de 36 alunos, havia iniciado o curso em março e concluído o estudo da disciplina em junho;-dela faziam parte estudantes aprovados por média' e outros após avaliação final realizada em junho.

É conveniente esclarecer:

$10^{\circ}$ - As situações de motivação e transferência eram diversas pois a turma T1 devia se preparar para a avaliação, porquanto de seu resultado dependia a aprovação na disciplina; as outras duas não.

$2 .^{\circ}$ - Salvo essa situação particular, era conveniente que os alunos náo se preparassem para o teste para evitar que o reforço, promovido por um reestudo que não poderiamos cortrolar, viesse a prejudicar a observação. Por isso, todas as demais aplicações de bateria de teste foi feita em horário de comunicações, oportunidade que nos permitia ter, a um mesmo tempo e de surpresa, a maioria dos alunos envolvidos na expeliência.

$3 .^{\circ}$ - Se o horário das comunicações atendia a essá finalidade, ficava entretanto prejudicado por outro aspecto: de acordo com a legislação então vigente, não era horário de frequência obrigatória. Por esse motivo, nem todos os alunos de todas as turn:as, responderam à avaliação prospectiva durante os quatro anos da observação . (3) - KRECH, David \& CRUTSCHFIELD, Ricard - Elementos de Psicologia. -
São Paulo, Pioneira, 1963. v.2 p 71.

R. Fac. Odont. P. A. 
Da avaliação final que foi aplicadà aos alunos da turma $\mathrm{T} 1$, selecionamos uma bateria de testes que haviam sido aplicados nas três turmas ao longo do curso e que passou a se constituir na avaliação prospectiva que aplicamos nas duas outras turmas em 1967 e a todas as três turmas nos anos seguintes.

o tempo decorrido entre o momento final do ensino e as avaliações prospectivas foi o que segue:

\begin{tabular}{|c|c|c|c|c|}
\hline Turma & 1967 & 1968 & 1969 & 1970 \\
\hline T. 1 & reforço & 12 meses & 24 meses & 36 meses \\
\hline T. 2 & 20 dias & 13 meses & 25 meses & 37 meses \\
\hline T. 3 & 3 meses & 15 meses & 37 meses & 39 meses \\
\hline
\end{tabular}

\section{RESULTADOS OBTIDOS}

A retenção de connecimentos está expressa em percentual médio por turma, cujos valores estão no quadro e gráfico que seguem:

\begin{tabular}{|c|c|c|c|c|}
\hline & 1967 & 1968 & 1969 & 1970 \\
\hline Turma T. 1 & $122.30 \%$ & $68.36 \%$ & $57.89 \%$ & $55.05 \%$ \\
\hline grupo (7) & $123.19 \%$ & $69.51 \%$ & $59.87 \%$ & $56.73 \%$ \\
\hline Turma T. 2 & $88.73 \%$ & $54.79 \%$ & $46.60 \%$ & $46.69 \%$ \\
\hline grupo (11) & $88.33 \%$ & $58.15 \%$ & $51.46 \%$ & $51.51 \%$ \\
\hline Turma T. 3 & $63.22 \%$ & $55.39 \%$ & $46.88 \%$ & $56.32 \%$ \\
\hline grupo (15) & $68.73 \%$ & $59.23 \%$ & $50.34 \%$ & $56.47 \%$ \\
\hline
\end{tabular}


TESTE DE SIGNIFICÂNCIA RELATIVO À TURMA T. 1

\begin{tabular}{|c|c|c|c|c|}
\hline Alunos & 1967 & 1970 & $37-70$ & $x^{2}$ \\
\hline 1 & 59 & 33 & 26 & 676 \\
\hline 2 & 46 & 26 & 20 & 400 \\
\hline 3 & 59 & 31 & 28 & 784 \\
\hline 4 & 45 & 12 & 33 & 1089 \\
\hline 5 & 55 & 37 & 18 & 324 \\
\hline 6 & 49 & 12 & 37 & 1369 \\
\hline 7 & 54 & 17 & 37 & 1369 \\
\hline $\mathrm{S}=59$ & $7=979$ & $\mathrm{~L}=6$ & 199 & 6011 \\
\hline
\end{tabular}

TESTE DE SIGNICÂNCIA RELATIVO À TURMA T. 2

\begin{tabular}{|c|c|c|c|c|}
\hline Alunos & 1967 & 1970 & $67-70$ & $\mathrm{x}^{2}$ \\
\hline 1 & 54 & 45 & 9 & 81 \\
\hline 2 & 50 & 28 & 22 & 484 \\
\hline 3 & 51 & 29 & 22 & 848 \\
\hline 4 & 53 & 38 & 15 & 225 \\
\hline 5 & 44 & 9 & 35 & 1225 \\
\hline 6 & 51 & 31 & 20 & 400 \\
\hline 7 & 44 & 34 & 10 & 100 \\
\hline 8 & 39 & 20 & 19 & 361 \\
\hline 9 & 55 & 32 & 23 & 529 \\
\hline 10 & 48 & 35 & 13 & 169 \\
\hline 11 & 5 & 25 & 30 & 900 \\
\hline $\mathrm{S}^{2}=63,8$ & $7=8,23$ & $\mathrm{GL}=10$ & 218 & 4958 \\
\hline
\end{tabular}

R. Fac. Odont. P. A. 
TESTE DE SIGNFICÂNCIA RELATIVO À TURMA T. 3

\begin{tabular}{|c|c|c|c|c|}
\hline Alunos & 1967 & 1970 & $67-70$ & $\mathrm{x}^{2}$ \\
\hline 1 & 23 & 9 & 14 & 196 \\
\hline 2 & 30 & 16 & 14 & 196 \\
\hline 3 & 28 & 27 & 1 & 1 \\
\hline 4 & 41 & 35 & 6 & 36 \\
\hline 5 & 40 & 42 & -2 & 4 \\
\hline 6 & 37 & 31 & 6 & 36 \\
\hline 7 & 42 & 28 & 14 & 196 \\
\hline 8 & 49 & 45 & 4 & 16 \\
\hline 9 & 21 & 20 & 1 & 1 \\
\hline 10 & 39 & 34 & 5 & 25 \\
\hline 11 & 51 & 36 & 15 & 225 \\
\hline 12 & 24 & 26 & -2 & 4 \\
\hline 13 & 33 & 30 & 3 & 9 \\
\hline 14 & 33 & 27 & 6 & 36 \\
\hline 15 & 34 & 29 & 5 & 25 \\
\hline $2=33,28$ & $\mathrm{t}=4,01$ & $\mathrm{GL}=14$ & 90 & 1006 \\
\hline
\end{tabular}

Os resultados apresentam significância estatística para 0,01

OBSERVAÇõES SOBRE A TURMA 1 (T 1)

A - Na aplicação do teste em 1967, a percentagem de retenção ultrapassa os $100 \%(123.19 \%$.

B - A queda de rendimento é sensivel após os 12 meses e depois diminui gradativamente, correspondendo a uma curva negativamente acelerada.

C - Não há diferença estatisticamente significante entre $o$ desempenho do grupo que realizou as quatro avaliações e $o$ da turma toda, sendo aquele levemente superior.

R. Fac. Odont. P. A. 
OBSERVAÇõES SOBRE A TURMA 2 (T 2)

A - Na aplicação do teste em 1967, quando passavam 20 dias do momen ${ }^{\dagger}$ de estudo, a percentagem de recordação baixou para $88.33 \%$.

B - A diminuição do rendimento é sensivel após 12 meses e depois tende à horizontalidade, correspondendo a uma curva negativamente acelerada.

C - Não há diferença estatisticamente significante entre o desempenho do grupo que realizou as quatrc avaliações e o da turma toda, senso aquele levemente superior.

\section{OBSERVAÇõEs SOBRE A TURMA} 3 (T 3)

A - Na aplicação do teste em 1967, quando passavam 3 meses do momento de estudo, o percentual de recordação baixou para $68.73 \%$.

B - A diminuição do rendimento é gradual até 1969 passando a um pequeno aumento, em 1970.

C - Corresponde a uma curva que, negativamente acelerada, ao final, torna-se positivamente acelerada.

D - Não há diferença estatísticamente significante entre $o$ desempenho do grupo que realizou as quatro avaliações e o da turma toda, sendo aquele levemente superior.

\section{DISCUSSÕES - CONCLUSõES - RECOMENDAÇõES}

A análise das curvas obtidas nos conduz, inicialmente, a uma afirmativa: numa primeira etapa o esquecimento é acentuado e, a medida que a. aplicação dos testes vai se afastando do momento de estudo, a retenção tende a se manter, aproximaciamente, estável.

Se considerarmos que os integrantes do primeiro grupo haviam se preparado para a avaliação, que os do segundo grupo tinham sido aprovados por média e que os do terceiro grupo estavam já distantes três meses do momento de ensino, verificamos que os percentuais de retenção respectivos (123.19-88.33-68.73\%) cstão harmônicos com a afirmação. No primeiro caso houve reforço, nos cemais houve um esquecimento já acentuado após 20 dias e 3 meses.

Grande parte da aquisição de conhecimentos é esquecida logo após a aprendizagem, continuando em rítimo mais vagaroso que tende a horizontalizar a curva.

Quer dizer que os resultados se asscmelham àquela observação inicial realizada em 1967 e, com a curva de EBB̈INGHAUS: são as curvas negativamente aceleradas tendendo a horizontalidade.

Uma segunda afirmativa é a seguinte: o percentual de retenção dos três grupos agora examinados mantem-se nos 2 últimos momentos da observação (de 24 a 39 meses) em torno de $50 \%$.

Será satisfatório?

Se desenvolvermos determinado 
conteúdo programático e procurarmos conduzir nossos alunos a estudá-lo é porque julgamos que o mesmo seja realmente necessário a sua formação. Não nos parece válido esperar que durante seu curso de graduação, mantenha-se recordando apenas a metade.

Como poderíamos tentar obter uma melhora?

Escolhendo apenas a metade mais significativa do conteúdo na expectativa de que o percentual de retenção pudesse chegar a $100 \%$ ? E se chegasse, deveríamos contentarmos ccm esse novo conteúdo?

E se ao contrário duplicarmos a' matéria a ser desenvolvida?

Continuaremos a obter o mesmo percentual?

Ou será melhor mudar a metodologia do ensino?

Outros trabalhos de observação semelhantes ao que agora relatamos, com a introdução de outras variáveis e em outras áreas de conhecimento, talvez possam ajudar a responder a essas perguntas.

Outro tópico a ser considerado é o papel da reaprendizagem.

$O$ efeito do reforço (reaprendizagem) parece influir até o final da observação T. 1 continua, até 1970 , com um rendimento ligeiramente mais elevado; T.3 que estava constituído por alguns alunos que também haviam reestudado a matéria em junho para fins de aprovação, apresenta o segundo lugar em rendimen- to; T.2 constituído exclusivamente por alunos aprovados por média, que não fizeram nenhum reestudo, chega ac final da experiência com o rendimento mais baixo.

\section{CONCLUSõES}

Uma vez que o maior coeficiente de esquecimento ocorre logo após o momento de estudo e que, de alguma forma, a repetição (reaprendizagem) parece exercer algum efeito na recordação do que é estudado, jugamos poder fazer as seguintes

\section{RECOMENDAÇÕES :}

$10^{\circ}$ - não fazer um exame ou avaliação ao final do trabalho de uma disciplina;

$2 .^{\circ}$ - nas verificações de aprendizagem realizadas com vistas a definição de um conceito final é conveniente que haja sempre matéria cumulativa (para forçar ao reestudo) ou que os conteúdos estejam organizados sequencialmente de tal forma que o aluno seja naturalmente conduzido ao reestudo;

$3 .^{\circ}$ - outros trabalhos semelhantes ao que é agora apresentado sejam levados a efeito em outras áreas do ensino superior, particularmente envolvendo alunos submetidos a diferentes metodologias de ensino. 